\title{
“12 ANOS DE ESCRAVIDÃO” E A PAIXÃO PELO REAL
}

\author{
Luís Gustavo Finger de Oliveira ${ }^{1}$ \\ Gabriel Steindorff ${ }^{2}$ \\ Fabiana Quatrin Piccinin ${ }^{3}$
}

\section{RESUMO}

Este artigo propõe uma reflexão sobre as narrativas audiovisuais contemporâneas marcadas pelo choque do real ou pela paixão pelo real. Em perspectivas semelhantes, os autores defendem a ideia de que, diante da experiência virtualizada e fragmentada atual, as produções audiovisuais construídas a partir da estética realista buscam ofertar um real mais real do que o real, portanto, explícito e contundente, buscando reduzir as mediações e artifícios em seu narrar. A observação deste fenômeno, bem como o estudo das estratégias de autenticação da linguagem audiovisual foram feitas no filme "12 Anos de Escravidão", de Steve McQueen, vencedor de três Oscars e integrante de uma safra de filmes oscarizados que, em boa parte, foram resultantes da retratação de histórias reais de anônimos.

Palavras-chaves: Real. Estética. Cinema. Narrativa. Choque do real.

\begin{abstract}
This article proposes a reflection on contemporary audiovisual narratives marked by real shock or the passion for real. In similar perspectives, the authors treat the idea that, given the current virtualized and fragmented experience, audiovisual productions built from the realist aesthetic try offer a more realistic real than real, so explicit and forceful, seeking to reduce the mediations and devices in their narration. The observation of this phenomenon, as well as the study of authentication strategies of audiovisual language were looked in the movie "12 Years of Slavery" by Steve McQueen, winner of three Oscars and a member of a crop of winning films that largely were resulting from the real stories of anonymous people.
\end{abstract}

Keywords: Real. Aesthetic. Movie. Narrative. Schock Real.

\section{O REAL COMO ESTÉTICA CONTEMPORÂNEA}

As estruturas narrativas construídas a partir do realismo estético, ocupadas em retratar as formas do real, têm por propósito uma intenção pedagógica traduzida justamente neste compromisso com a legitimação dos fatos. No que diz respeito às narrativas realistas do contemporâneo, estas emergem com força de maneira global e evidente, especialmente nos

\footnotetext{
${ }^{1}$ Aluno do Curso de Comunicação Social - Jornalismo da Universidade de Santa Cruz do Sul (UNISC). luis.gustavo.f.o@hotmail.com>

${ }^{2}$ Aluno do Programa de Pós Graduação - Mestrado em Letras da Universidade de Santa Cruz do Sul (UNISC). gabriels@unisc.br

${ }^{3}$ Professora do Curso de Comunicação Social e do Programa de Pós Graduação - Mestrado em Letras (UNISC Universidade de Santa Cruz do Sul). fabi@unisc.br
} 
temas afeitos à violência marginal ou em representações do dia a dia que detalham, em maior ou menor grau, os obstáculos experimentados especialmente pela retratação de vidas anônimas (JAGUARIBE, 2010).

A ascensão da estética realista pode ser explicada pela habilidade, segundo Jaguaribe (2010), em prover vocabulários que facilitem o entendimento da experiência contemporânea. Ou seja, para a autora, o realismo toma os retratos de intensidade dramática e de narrações do desmanche social para aumentar a acessibilidade de leitores e espectadores, comprovando assim o papel educativo da realidade que possui. (JAGUARIBE, 2010). A ficção, neste sentido, vale-se de suas estratégias de intensificação dramática na busca por mostrar a "vida como ela é", em mundos que ofertem esclarecimentos acerca da experiência contemporânea.

Investem, portanto, na oferta de representações dotadas de autenticidade com relação ao real, segundo Gomes (2012), descrevendo cenas de violência explícitas que expressam e demonstram um novo cenário de um realismo brutal e cruel, visto em emergência em meio à diversidade de temas e formatos de narrativa. Assim, diferentemente das estéticas românticas, fantásticas ou surreais, Jaguaribe (2010) explica que essas ficções realistas se valem do senso comum cotidiano, sustentadas na verossimilhança, incidindo de maneira crítica e incisiva nas mazelas sociais. E ainda que esses códigos realistas não cheguem a desestabilizar a noção da realidade, fortalecem sua exposição na medida em que marcam presença na fotografia, cinema, literatura e meios de comunicação, definindo-se como senso comum que permite mediar a compreensão do cotidiano dos indivíduos na contemporaneidade.

Dessa maneira, percebe-se que as estéticas do realismo objetivam capturar o que se entende por formas habituais pelas quais os sujeitos manifestam seus problemas existenciais, ainda que relativas a situações limite, através de experiências subjetivas e sociais que auxiliam na construção desta realidade. E permitindo a promoção, por consequência, da potencialização dos imaginários possíveis frente às situações de exceção retratadas como maneira possível de tornar o cotidiano que é amorfo, fragmentário e dispersivo em uma experiência mais significativa.

Jaguaribe (2010) justifica a naturalização dos códigos do realismo como caminho para assimilar o cotidiano como uma dinâmica consequente da globalização cultural. Para a autora, as narrativas que remetem ao real estão em emergência por conta do enfraquecimento dos discursos e epistemologias que até então serviam de referência a uma época marcada pelas ágeis transformações significativas, que privilegiam o presente em relação ao futuro, e ainda indicam novas maneiras de narrar as experiências cotidianas, mais sustentadas na efemeridade das relações. 
A visão relativista, assim, desfaz as concepções antes aceitas como verdadeiras da era moderna, por conta de, neste momento, se mostrarem incapazes de ofertar a compreensão possível frente às vivências cotidianas. Há, portanto, um desmoronamento das crenças absolutas, calcadas previamente na norma explícita, que não mais possibilitam a transformação confortadora.

Trata-se de um tempo outro que bem combina com a definição trazida por Jaguaribe sobre a estética realista, quando refere sua oposição ao devaneio fantasioso. Segundo a autora, o realismo contemporâneo marca uma “ ...visão de mundo que exclui ou coloca em quarentena fantasias, crenças esotéricas, tradições místicas ou sonhos românticos que também se manifestam na fabricação social da realidade na modernidade" (JAGUARIBE, 2010, p. 17). Também Zizek (2003) evidencia que a paixão pelo real se traduziu no século $X X$ como uma alternativa ao centramento da utopia do século XIX, como a realização direta da esperada Nova Ordem, a coisa em si. Ou seja, vive-se o "tempo do real" em manifestações narrativas de violência extrema tomadas como estratégia afirmadora contra a angústia insuportável de se sentir inexistente.

No entanto, estas marcas emergentes do realismo deste tempo observadas nas explicitudes e contundências de temas e formas de representação do real acabam por suplantar a própria intenção do que pretendem representar. No universo globalizado, construído sob a intervenção midiática, observa-se a superprodução de imagens de realidade exageradas impulsionadas pelo "dever indispensável" em apresentar novidades, bem como à sua motivação pelas narrativas de choque.

Em razão disso, mais vale a representação contundente do evento do que o evento em si. Um fenômeno que Martins (2010) vai chamar de "desreferencialização", marcado justamente pela sensação de ausência do referente que passa a ser imageticamente substituído por sua representação dando origem ao que Baudrillard (1991) chama de hiper-realidades. Neste contexto, a representação naturalista já não é mais suficiente em detrimento do apelo às hiperimagens que, mais do que nunca, se anunciam como registros mais significativos e mais sedutores. Mais reais do real. (PICCININ, 2014).

Barthes (1988) já observava, ao se referir ao romance realista do início do século $\mathrm{XX}$, que o efeito do real pode ser percebido por meio de caracterizações particularizadas que atribuem mais credibilidade ao espaço e à construção dos personagens. No entanto, a narrativa realista do século XXI vem marcada por um acento nesta oferta da realidade produzindo o que Jaguaribe (2010) chama de "choque do real". E que tem a intenção declarada de atingir o espectador-leitor ao causar desconforto, provocando o efeito de espanto catártico. 
Conforme explica Jaguaribe (2010, p. 100):

\begin{abstract}
O impacto do "choque" decorre da representação de algo que não é necessariamente extraordinário, mas que é exacerbado e intensificado. [...] O "choque do real" tem como finalidade provocar o espanto, atiçar a denúncia social, ou aguçar o sentimento crítico. Isto é, o choque do real quer desestabilizar a neutralidade do espectador/leitor sem que isto acarrete, necessariamente um agenciamento político.
\end{abstract}

Gomes (2012, p. 73) também problematiza as representações de real ao trazer como exemplo uma declaração do diretor de cinema Martin Scorsese “(...) me pergunto por que se veem hoje cada vez mais efeitos especiais que mostram corpos mutilados ou em decomposição". Referia-se o cineasta italiano a um suposto movimento de naturalização da violência alentada pela guerra das imagens e pelo recrudescimento das polêmicas sobre a violência na televisão e no cinema. Segundo o cineasta (apud Gomes), os anos 1990 registraram-se de fato uma grande quantidade de produções cinematográficas que exploravam a violência tomando o espectador de assalto, além de uma obsessão pelo serial killer.

\title{
2 A PAIXÃO PELO REAL E O REALISMO DESREFERENCIALIZADO
}

Enquanto Jaguaribe aponta o século XXI como o tempo da emergência do choque do real, para Zizek (2003) este é o tempo da paixão pelo real, da busca, segundo ele, da coisa real, da realidade destituída o quanto possível de mediações e artifícios. Essa paixão pelo real, constitui, através de uma rede de semblantes, a nossa realidade, culminada na emoção pelo real como efeito último. Assim, o indivíduo sente necessidade de perceber os produtos audiovisuais como frutos da realidade, muitas vezes, mesmo como a própria realidade nua e crua. Isso justifica, para Zizek, o aparecimento de reality shows, pornografia amadora e snuff movies ${ }^{4}$. Esses últimos filmes "oferecem a verdade nua e crua, e são talvez a verdade última da Realidade Virtual" (ZIZEK, 2003, p. 26). Segundo o mesmo autor:

\begin{abstract}
A Realidade Virtual simplesmente generaliza esse processo de oferecer um produto esvaziado de sua substância: oferece a própria realidade esvaziada de sua substância, do núcleo duro e resistente do Real - assim como o café descafeinado tem aroma e gosto do café de verdade sem ser o café de verdade, a Realidade Virtual é sentida como realidade sem o ser. Mas o que acontece no final desse processo de virtualização é que começamos a sentir a própria "realidade real" como uma entidade virtual. (ZIZEK, 2003, p. 25)
\end{abstract}

\footnotetext{
${ }^{4}$ Snuff significa morte, assassinato, e é o título de um filme produzido na década 1970 cuja propaganda afirmava que os atores que representavam personagens assassinados foram realmente mortos durante a filmagem. Indica um tipo de filmes de horror dedicados a sexo e violência, em que a violência não é simulada. (ZIZEK, 2013, p. 25)
} 
Dessa maneira, a "realidade real" tem sua credibilidade abalada pelo tanto de virtualização. Semelhante a um programa de televisão, os indivíduos do século XXI estão cercados de câmeras por todos os lados. Há câmeras de vídeo que cuidam da segurança de lojas, câmeras que fotografam motoristas infratores no trânsito e até câmeras de vídeo que equipam aviões de guerra não tripulados. Todo este aparato possibilita que o indivíduo pressuponha participar remotamente de eventos aos quais não esteve presente, por meio de registros ou, em alguns casos, até em tempo real.

Por esta razão, a aparente realidade, segundo Zizek (2003), já não basta. É preciso apegar-se em algum fator incontestavelmente real. O que resulta em paradoxo, se a paixão pelo Real termina no puro semblante do espetacular efeito de Real, então, em exata inversão, a paixão pós-moderna pelo semblante termina numa volta violenta à paixão pelo Real. (p. 2324) Ou seja, ao buscar de forma virtualizada uma realidade real, o indivíduo não se contenta com fatores que podem ser postos em dúvida a respeito de sua legitimidade, por isso utiliza-se de fatores como a dor para validar o que é real.

\begin{abstract}
Vejamos o exemplo, das pessoas, geralmente mulheres, que sentem uma necessidade irresistível de se cortar com lâminas ou de se ferir de outras formas; trata-se de um paralelo exato da virtualização de nosso ambiente: representa uma estratégia desesperada de volta ao Real do corpo. $\mathrm{O}$ ato de se cortar pode ser comparado, em si, às inscrições tatuadas no corpo, que simbolizam à inclusão daquela pessoa numa ordem simbólica (virtual) - o problema das pessoas que se cortam é exatamente oposto, ou seja a afirmação da própria realidade. Longe de ser uma atitude suicida, longe de indicar um desejo de autoaniquilação, o corte é uma tentativa radical de (re) dominar a realidade ou, o que é outro aspecto do fenômeno, basear firmemente o ego na realidade do corpo contra a angústia insuportável de se sentir inexistente. (ZIZEK, 2013, p. 24)
\end{abstract}

Deve-se considerar que as expressões dessa nova estética do real não se apresentam apenas na televisão ou em audiovisuais documentais. Figueiredo (2010) identifica o interesse cada vez maior, por parte do público, do que ela chama de "histórias verdadeiras". Ou seja, há um interesse em histórias de pessoas não famosas, o que causa semelhança e empatia, por parte do espectador em relação ao personagem. Assim adentra-se na coisa real, como no conceito de Zizek (2003) e reforça-se a credibilidade do filme.

Figueiredo (2010) explica que revistas que tratam de pessoas não famosas, reality shows e o cinema documental - e aqui podemos inserir também o cinema não ficcional como uma variável, já que não se apresenta exatamente como o documental - como uma tendência da "busca do real como matéria bruta, acompanhada de uma rejeição do ficcional". (p. 70) 
Isto, para a autora, caracteriza não só um movimento de retorno à estética realista, mas uma necessidade urgente do que chama de neorrealismo contemporâneo.

Para a autora, no neorrealismo, a objetividade ou transparência de um narrador intelectual, aquele que percebe a situação do outro a narra e organiza, não é o que exatamente confere credibilidade à narrativa. $\mathrm{O}$ que autentica a narrativa como verídica efetivamente é o lugar de onde se fala. Ou seja, a autenticação da narrativa como real se dá, não pela observação de um indivíduo de fora da história, mas por um personagem que narra através de sua experiência como protagonista da ação. Assim, se as obras realistas tradicionalmente davam ao leitor a impressão de que se
defrontava com um discurso sem regras, a não ser a de representar sem distorções o
real, assegurando um contato imediato com o mundo tal como ele é, a vertente de
realismo que se tornou predominante, hoje, caracteriza-se por valorizar o
envolvimento do narrador com o fato narrado, isto é, a falta de distanciamento e a
intimidade da abordagem, que são tomadas como prova de sinceridade - o que
permitiria ao leitor ou espectador aproximar-se das verdades particulares, parciais.
Ou seja, a ênfase não recai num realismo da representação, mas num realismo de
base testemunhal, apoiado na narração que se assume como discurso.
(FIGUEIREDO, 2010, p. 73-74)

A autora ainda observa que a fotografia pode se apresentar de formas diferentes, dependendo da interpretação da imagem percebida. Existem as fotografias que são percebidas como encenação ou produções fictícias para serem registradas e fotografias percebidas como registro de um evento real. As fotografias do primeiro tipo são descartadas de toda a realidade. As fotografias do segundo tipo carregam informações de realismo, muitas vezes sutis, como a simples presença do fotógrafo em determinado lugar ou até mesmo um enquadramento mais rudimentar. No aspecto fotográfico pode-se dizer que, quanto menos profissional, mais real parece.

$\mathrm{O}$ aspecto fotográfico também se reflete no cinema, já que este deriva da linguagem fotográfica. Neste meio observam-se enquadramentos em que a câmera simula a visão humana, e para se criar este efeito, há de se rejeitar em parte a perfeição do enquadramento. Entretanto, no cinema, há maiores complicações. Segundo Figueiredo (2010), o realismo cinematográfico está frequentemente em discussão já que a instância enunciadora não está em evidência. Ou seja, no cinema, quem narra a história nem sempre é quem a vocaliza, mas geralmente quem a organiza. O narrador seleciona o ponto de vista do espectador através de um aparato narrativo que tem na câmera seu recurso principal. Outro fator que põe à prova o realismo cinematográfico é apresentar sempre no presente situações passadas. 
Ao mesmo tempo, as técnicas digitais e a evolução contínua da computação gráfica trazem ao cinema um fator que rediscute a dicotomia entre a estética realista e a estética antirrealista.

\begin{abstract}
O computador, a nova tecnologia da informática, introduz possibilidades inéditas de montagem e justaposição de imagens, dando origem a formas hibridas que, de certa maneira, contribuem para a conciliação entre esses dois polos. Podem-se combinar, com uma precisão quase perfeita, imagens de uma grande variedade de fontes distintas, como, por exemplo, imagens de arquivo, imagens em movimento geradas no computador e uma ação encenada. A nova técnica de manipulação de imagens permite também a distorção e a modificação de imagens, a produção de alterações indetectáveis em imagens fotográficas, de vídeo e cinematográficas já existentes. (FIGUEIREDO, 2010, p. 79)
\end{abstract}

Esta mistura de imagens confere ao cinema maior impressão de legitimidade narrativa, mostrando em cenas de violência, por exemplo, maior detalhamento. Ao perceber o sangue jorrando e respingando na lente da câmera, o espectador tem uma ligeira sensação de confusão porque ao mesmo tempo em que o sangue cênico respinga, a lente da câmera se revela. Se mostrando, o aparato, confere à narrativa a legitimidade de uma testemunha da ação.

A estética realista no cinema, conforme Aumont (2009) se configura como uma espécie de narrativa que implica em um composto de códigos que são capazes de levar ao público a interpretação da imagem como algo semelhante em associação à percepção do real. Neste sentido, Aumont (2009) salienta que a riqueza perceptiva dos conteúdos dos filmes, da imagem e do som compõem aquilo que define como impressão de realidade produzida pelos filmes realistas.

Observa-se assim, como propõe Figueiredo (2010), que a montagem cinematográfica buscou adaptar-se em função da sociedade do século XXI e seu "bombardeio" por imagens em movimento, vindas de diferentes lugares do mundo, que tentam esconder ao máximo o seu artifício estético. Para ela, através dessas "novas técnicas de fabricação de imagens, o realismo contemporâneo mostra-se relacionado, então, com o que desvenda as próprias mediações ou com o que parece ser espontâneo, sem artifícios, precário.” (FIGUEIREDO, 2010, p. 80) 


\section{MARCAS DO REAL: ANÁLISE DO FILME “12 ANOS DE ESCRAVIDÃO”}

A proliferação de narrativas baseadas em histórias reais de pessoas anônimas pode ser percebida atualmente como tendência em ofertar ao espectador a realidade autenticada, livre de mediações e artifícios, tanto quanto isso pode ser possível. Desse modo, pode-se verificar entre outras marcas, a do narrador em terceira pessoa que passa a ser substituído pela narração testemunhal, conforme Figueiredo (2010), por apresentar maior envolvimento do narrador com o fato narrado. Isto, segundo a autora, gera uma "falta de distanciamento e a intimidade da abordagem, que são tomadas como prova de sinceridade - o que permitiria ao leitor ou espectador aproximar-se das verdades particulares, parciais. (FIGUEIREDO, 2010, p.74).

No âmbito do cinema, observa-se que por ocasião da premiação do Oscar 2014 uma das maiores premiações do mundo na área - dos nove filmes concorrentes na categoria "Melhor Filme", quatro eram de fato narrativas baseadas em histórias reais de anônimos e que são narradas de forma testemunhal. Entre estes filmes premiados e que apresentam estas características estruturais e temáticas destaca-se "12 Anos de Escravidão", de Steve McQueen. A produção levou, pela competência narrativa de reconstrução de uma "realidade", três Oscars - melhor filme, melhor atriz coadjuvante e melhor roteiro adaptado.

O filme, que impacta pela crueza de suas sequências de cenas violentas, é baseado no livro escrito por Solomon Northup, que conta a sua história real. Um homem negro que nasceu livre, até ser preso e vendido como escravo e viver nesta condição por 12 anos. Sua contundência está presente tanto no que diz respeito à diegese quanto à forma narrativa, marcada pela explicitude das cenas. Solomon Northup, vivido pelo ator Chiwetel Ejiofor, é um homem negro, livre que trabalha como violinista e que vive com sua esposa e dois filhos em Saratoga Springs, Nova Iorque na metade do século XIX.

Porém, Northup recebe de dois homens uma oferta de emprego de duas semanas como músico em Washington. Já na cidade onde acreditava que iria trabalhar, é embriagado e levado para uma senzala, onde percebe, após apanhar muito, que está preso como um escravo. Depois disso, Northup é colocado juntamente com outros negros capturados e enviado para o sul do país, em Nova Orleans, Louisiana, onde a escravidão ainda era permitida à época. A partir daí, é imposto ao violinista, homem de fino trato e formação, uma nova identidade e história. Seu novo nome seria Platt, um escravo capturado como fugitivo na Geórgia.

Ao longo do filme, a história de Northup se desenvolve em torno do sofrimento e da dor causado pelo sequestro, a submissão ao trabalho escravo e os castigos físicos e a saudade 
de sua família. Depois de ser escravizado por 12 anos, Northup consegue conquistar sua liberdade e voltar para sua família. O violinista tenta processar seu ex-patrão e os dois homens que o enganaram, mas nos créditos finais é possível ver a impotência e fraqueza de um negro contra um branco na justiça da época.

\subsection{Estratégias de análise do real autenticado}

Para dar conta da análise do filme observando a presença de elementos audiovisuais autenticadores do real, a partir da observação inicial do filme, elencaram-se assim três características resultantes de padrões de repetição da narrativa. Neste sentido, verificou-se a) o posicionamento de câmera, b) plano-sequência como unificador temporal, c) câmera na mão como efeito de real que seguem aplicados a cenas escolhidas por sua representatividade e riqueza do ponto de vista narrativo para análise pretendida. Neste sentido, mostram-se neste artigo como alguns dos exemplos possíveis de serem estudados se encaixam no âmbito da análise proposta neste artigo.

\subsubsection{Posicionamento da câmera como autenticador do real}

Os enquadramentos de câmera, ao longo do filme, vão indicando sua intencionalidade de potencializar o sentido contundente do que está sendo proposto. Uma das sequências paradigmáticas dessa natureza acontece quando, após aceitar um emprego que o leva para outra cidade, Solomon Northup (representado pelo ator britânico Chiwetel Ejiofor) é embebedado em um jantar com seus contratantes. Posteriormente acorda em um local não identificado onde percebe que está acorrentado, o que o faz, a partir de então, buscar na memória os acontecimentos da noite anterior que possam explicar a sua atual situação.

Nesse momento, dois homens desconhecidos entram no galpão em que Solomon se encontra. Este tenta, sem sucesso, convencê-los de que é livre e mora em Nova Iorque com sua família. Um deles pede para que Solomon, então, mostre os documentos de sua liberdade que, na condição de sequestrado, não tem e, portanto, não pode se identificar. Após uma breve discussão, o segundo homem se aproxima do agora escravo e o derruba puxando a corrente que prendia suas mãos. Caído no chão, Solomon é espancado com um pedaço de madeira. Neste momento, a câmera se desloca para próximo do escravo, projetando seu ângulo de visão para baixo de modo a colocar o espancador em uma posição de superioridade em relação ao Solomon. 
Nesta cena, percebe-se a intenção do diretor de, a partir da explicitude da violência, construir uma cena com a câmera de cima para baixo, mostrando o ator de mãos e joelhos ao chão, em sua condição de indignidade e submissão. A sequência se constrói com cenas de violento espancamento do homem nascido livre reduzido à condição indigna de animal. A superioridade e dominação da perspectiva dos agressores se dá por este enquadramento que se traduz em suas visões de mundo.

Além disso, o enquadramento de cima para baixo para criar a ideia de inferioridade e indignidade de Solomon é potencializado pelas estratégias de efeito de real barthesiano ali presentes, como a riqueza dos detalhes da direção de cena - desde cenário, roupa e diálogos somados à competência dramática dos atores. Esse conjunto de elementos bem dirigidos resulta numa sequência narrativa de extrema violência "autêntica" capaz de gerar no espectador o que Zizek (2013) aponta como o movimento de alcançar a "coisa real" que as narrativas podem ofertar. Ou seja, o espectador, neste espanto catártico produzido pelas cenas "reais" de dor e crueza, torna-se partícipe ação e identificando-se com o processo degenerativo de Solomon.

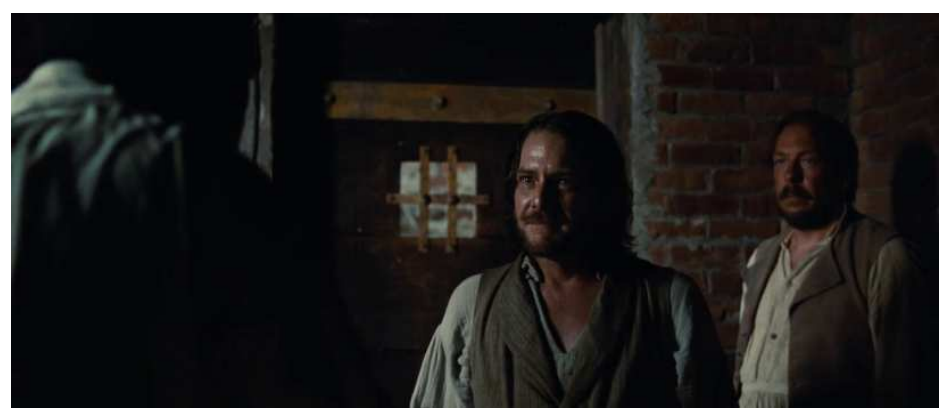

Legenda: Cena que Solomon discute com os capatazes na tentativa de argumentar que é um homem livre Fonte: 12 Anos de Escravidão (2013)

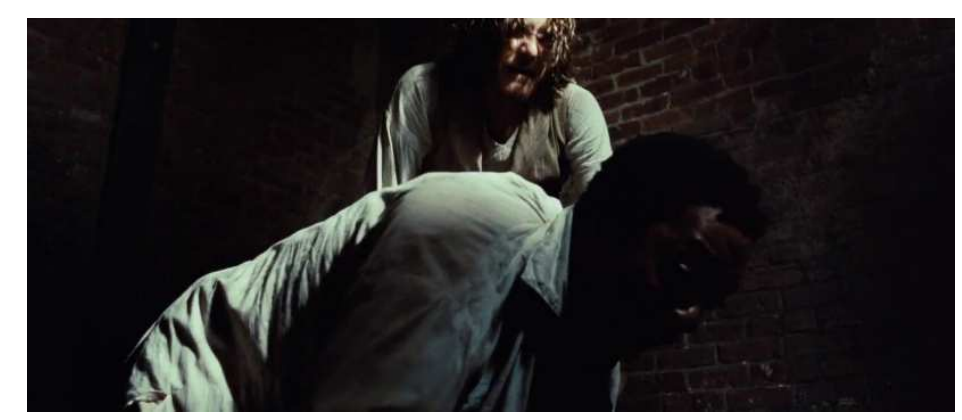

Legenda: O plano debaixo para cima com o objetivo de mostrar a superioridade do capataz branco. Fonte: 12 Anos de Escravidão (2013) 


\subsubsection{Plano-sequência como unificador temporal}

Outro recurso explorado para autenticar a realidade apresentada no filme diz respeito ao uso do plano sequência em que a câmera é ligada e mostra o desenrolar do acontecimento sem interrupções, ou seja, sem ser desligada. Um bom exemplo do efeito potencializador da autenticidade deste real é mostrado quando Solomon, vendido como escravo para um fazendeiro chamado Sr. Ford, tem um desentendimento com o capataz durante o trabalho de construção de uma casa e é levado à morte por ele.

Durante a briga, ousadamente, Platt revida a agressão do superior que, como vingança, recruta dois homens para tentar enforcá-lo em uma árvore. No entanto, são surpreendidos por um quarto homem que frustra a tentativa de enforcamento por conta de alertá-los que o dono do escravo, Sr. Ford, tem Platt como hipoteca. Deste modo, se o escravo morresse, os homens teriam que dar conta da dívida do fazendeiro, o que faz com que os carrascos abandonem Platt ali, ainda amarrado pelo pescoço a uma corda que, por sua vez, está amarrada a uma árvore. E por essa razão ele precisa ficar na ponta dos pés para não ser enforcado porque, ao menor deslize seus pés alcançariam o chão, fazendo com que a corda corresse e apertasse o pescoço até a morte.

Nesta cena, há a alternância entre dois longos planos-sequências que colaboram para a potencialização do sofrimento e da angústia da sequência das cenas numa perspectiva metalinguística. Em um primeiro momento, a câmera focaliza os pés de Platt na lama buscando a todo custo manter-se equilibrado e em pé, para não ser enforcado. Já a segunda cena mostra um plano geral em que se percebe Platt, em primeiro plano, lutando pela vida e, ao fundo, outros escravos seguindo com suas rotinas, indicando que estes deveriam ignorar Platt e sua luta contra morte, se quisessem salvar as suas vidas.

$\mathrm{Na}$ segunda cena, quando a câmera se fixa no enquadramento de Platt de corpo inteiro lutando insistentemente para não deixar os pés pousarem no chão, a sequência de cena se dá em plano-sequência de aproximadamente 1 min e 30seg. É uma câmera parada num plano geral que mostra Platt debatendo-se no limite entre a vida e a morte e que, portanto, gera no espectador uma angústia que se apresenta "interminável”, porque esse tempo do assistir a cena está, pelo plano sequência - sem edição - “compatível” com a duração do evento na realidade.

Como diz Geada (1985, p. 72), “a realidade vista e ouvida no seu acontecer é sempre no tempo presente. O tempo do plano-sequência, entendido como elemento esquemático e primordial do cinema, - ou seja: como um plano-subjectivo, infinito - é assim o presente". 
Nesta sequência de cena, também é bom lembrar que os avanços tecnológicos e a consequente fidelidade da imagem proporcionada no caso do filme, aumentam a impressão de realidade. E consequentemente, oferta ao espectador um momento de angústia efetivamente gerada por uma cena que tem, além desta fidelidade capaz de fazer crer, na ilusão do cinema, que isto está se passando de fato, também o sentido de uma dor que não acaba nunca como de fato são os intensos mal estares na vida dos indivíduos.

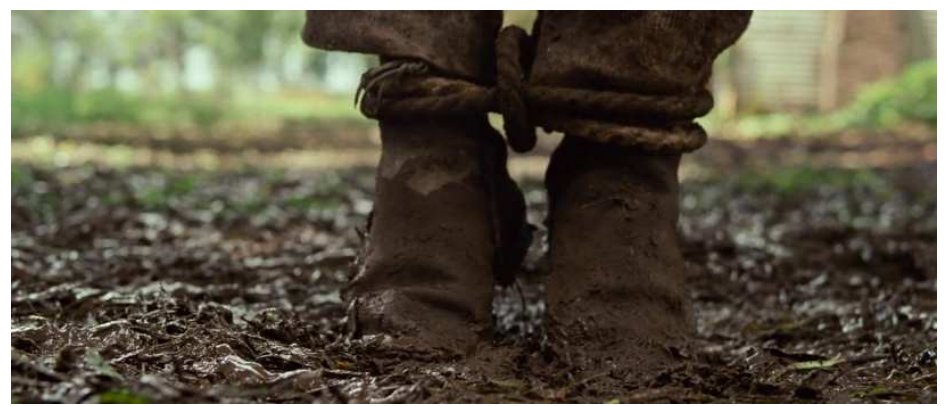

Legenda: Plano fechado que mostra o escravo nas pontas dos pés na luta por sua vida Fonte: 12 Anos de Escravidão (2013)



Legenda: Plano aberto que mostra os escravos realizando suas atividades naturalmente, enquanto o escravo se mantém na ponta dos pés lutando para sobreviver Fonte: 12 Anos de Escravidão (2013)

\subsubsection{Câmera na mão como efeito de real}

Outro recurso recorrente utilizado como construtor da oferta de um real potencializado diz respeito ao uso da câmera em plano-sequência e sem o uso - intencional do tripé. É uma amostra da estratégia de redução da mediação e dos artifícios na narrativa do real em imagem e som da mesma maneira que em sua natureza bruta, onde de fato não recebe tratamentos editoriais.

No trecho escolhido para análise, Platt já se encontra em outra fazenda, desta vez comandada pelo Sr. Epps. A cena inicia com Epps procurando por Patsey, uma escrava que o proprietário achou ter fugido ou ter ido namorar com o outro patrão. Quando a escrava 
retorna, Epps, furioso por conta de a escrava ter saído sem sua permissão, a coloca nua no tronco e decide puni-la, pedindo a Platt que a açoite. O escravo hesita por um momento, mas acaba por fazê-lo porque sabe que a desobediência pode resultar em punição também a ele.

No entanto, ao assistir a aplicação do castigo por Platt, o senhor de escravo o interrompe, acreditando que este não imprime a força necessária para puni-la devidamente e toma das mãos dele o chicote. A partir de então, o açoite se dá de uma forma muito cruel e violenta, potencializada pela adoção de um plano-sequência que dura aproximadamente cinco minutos. No plano sequência, observa-se tremores de câmera por esta estar, durante todo este tempo, no ombro ou na mão. O que contraria os preceitos tradicionais do cinema, posto que uma cena longa como esta exigiria ser filmada no tripé para garantir, justamente, que não saísse tremida.

No entanto, desta vez, as imagens tremidas proporcionam um efeito de veracidade à narrativa, bem como a sensação de acompanhamento do acontecimento por parte do espectador como diz Winston (apud SULZBACH, 2006, p. 247). Segundo o autor, (...) a câmera na mão tornou-se uma marca central da verdade cinemática. Isto é, a câmera na mão, tão utilizada como recurso para efeito documental, também é usada na ficção na busca por ofertar autenticidade às imagens. E de fato, a sequência de cena resultou numa narrativa de intensa carga dramática associada ainda aos recursos dos efeitos especiais que mostram, com muito realismo, as costas da escrava sendo dilaceradas pelo açoite.

Do mesmo modo que as imagens constroem o real em contundência, também nesta cena, auxiliam neste processo a utilização de recursos sonoros, que proporcionam um toque sofisticado à história, dando ritmo e o tom, muitas vezes, do que pode acontecer na trama. Conforme afirma Vela (1998, p. 61), a música é um indicador que compõe o cenário do filme. Através dela, o espectador é orientado a sentir e perceber a cena conforme o projetado pelo narrador.

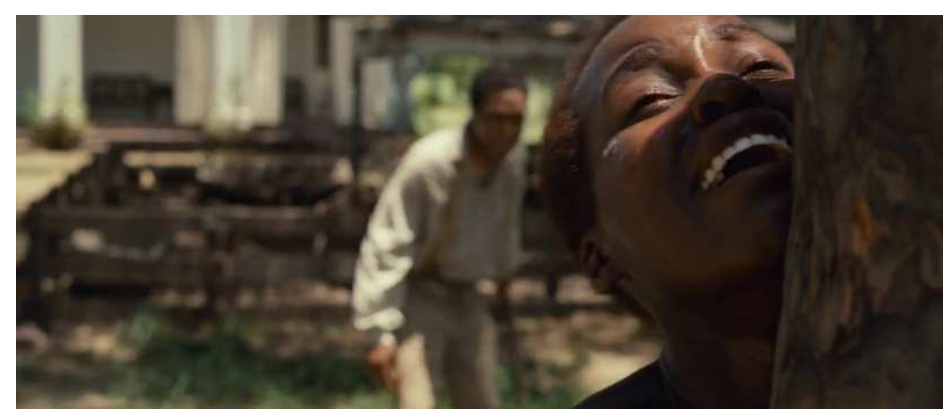

Legenda: Cena que mostra os dois escravos em posições diferentes e também momento em que Platt é obrigado a açoitar outra escrava.

Fonte: 12 Anos de Escravidão (2013) 




Legenda: Segunda cena que Platt, agora, ajuda a desamarrar a escrava Fonte: 12 Anos de Escravidão (2013)

\section{CONSIDERAÇÕES FINAIS}

A partir deste estudo que buscou mostrar as marcas do real em uma produção cinematográfica específica, pode-se notar a tendência de as narrativas audiovisuais em assumirem histórias reais e de anônimos no que diz respeito ao tema e de maneira explícita e contundente - muitas vezes brutal e explícita da violência - no que diz respeito à forma.

Essa tendência estudada no filme "12 anos de escravidão" apresenta-se em conformidade com a proposta de ofertar o real em sua plenitude e força como resposta possível a esta experiência tão fragmentária e dispersa que marca o contemporâneo. E neste sentido, a análise do filme possibilitou compreender que o efeito de real é uma construção que demanda escolhas de linguagem, de técnicas e de recursos capazes de contribuir em tudo para a autenticidade do relato. A valoração do real disse respeito especialmente ao tratamento adotado na construção imagética e sonora que privilegiou o sentido produzido pelas imagens em consonância com o sentido proposto pela sequência de cena analisada no sentido de potencializar a crueza, a contundência e a explicitude da violência e da dor como autenticadores de realidade.

\section{REFERÊNCIAS}

ANDRADE, A. L. O filme dentro do filme: a metalinguagem no cinema. Belo Horizonte. UFMG, 1999.

AUMONT, J. et al. A estética do filme. 7. ed. São Paulo: Papirus, 2009.

BARTHES, R. O rumor da língua. São Paulo: Brasiliense, 1988.

BAUDRILLARD, J. Simulacros e simulação. Lisboa: Relógio D'Água, 1991. 
FIGUEIREDO, V. L. F. de. Narrativas migrantes: literatura, roteiro e cinema. Rio de Janeiro: PUC-RJ, 2010.

GEADA, E. Estéticas do Cinema. Lisboa: Publicações Dom Quixote, 1985.

GOMES, R. C.; MARGATO, I. (Orgs). Novos realismos. Belo Horizonte: UFMG, 2012.

JAGUARIBE, B. O choque do real: estética, mídia e cultura. Rio de Janeiro: Rocco, 2007.

MARTINS, B. G. Sinto, logo existo: real e verdade na experiência contemporânea. In: COMPÓS Associação Nacional dos Programas de Pós Graduação, 18., Belo Horizonte, 2009. Disponível em: < http://www.compós.org.br >. Acesso em: 25 maio 2010.

MERTEN, L. C. Cinema: entre a realidade e o artifício: diretores, escolas, tendências. 2. ed. Porto Alegre: Artes e Ofícios, 2005.

MCQUEEN, S. 12 anos de escravidão. São Paulo: River Road Entertainmen, 2014.

SULZBACH, L. Breve relato sobre o documentário segundo Karel Reisz. In: DUARTE, E. B. D. CASTRO, M. L. D. (Orgs). Televisão: entre o mercado e a academia. Porto Alegre: Sulina, 2006.

VELA, H. Quando a música e o discurso geram caos. In: MEDITSCH, E. (Org.). Rádio e pânico: a Guerra dos Mundos 60 anos depois. Florianópolis: Insular, 1998.

ZIZEK, S. Bem-vindo ao deserto do real!: cinco ensaios sobre o 11 de setembro e datas relacionadas. São Paulo: Boitempo, 2003. 